\title{
HEMANGIOENDOTELIOMA MALIGNO DO CRÂNIO: RELATO DE UM CASO EM CRIANÇA
}

\author{
Walter C. Pereira * \\ Antonio J. Chagas ** \\ PEDRO G. LOPES **
}

\author{
ANTONIO B. LeFÈVRE *** \\ ROLANDo A. TENUTO **** \\ L. C. Mattosinho-França $* * * * *$
}

Os tumores de origem vascular sangüinea são muito raros, particularmente aquêles com localização óssea primária. Até 1956 Carter e col. ${ }^{4}$ encontraram registrados na literatura apenas 16 casos, acrescentando mais um de sua própria observação. Em 1965 Glasser e Reichmann ${ }^{7}$ publicaram nôvo caso e citaram um outro de Blattner como os únicos registrados na Alemanha. Além da grande raridade, tais neoplasias exibem características interessantes, entre as quais avulta a dificuldade nos diagnósticos clínico e radiológico, principalmente em crianças onde sua ocorrência é excepcional.

Recentemente tratamos uma criança com hemangioendotelioma maligno situado no crânio, cujo registro nos parece útil em virtude da inexistência de caso semelhante publicado em nosso meio e da dificuldade diagnóstica suscitada pelo aspecto radiológico do tumor.

\section{OBSERVAC A $\mathrm{O}$}

D.P.A., 6 anos de idade, sexo masculino, côr branca, registro H.C. 813606 . O paciente foi admitido em 12-5-1967 com história iniciada 9 meses antes, caracterizada pelo crescimento progressivo de duas tumoraçōes na cabeça, relacionadas, pelos familiares, a traumatismo da região frontoparietal esquerda; à medida que cresciam, as massas tumorais iam confluindo até juntarem-se numa única. Tais tumorações sempre foram indolores, não causando sintomatologia alguma. Nos antecedentes pessoais e familiares do paciente nada foi averiguado que tivesse relação com a moléstia, a não ser o traumatismo já mencionado. Exame clínico-neurológico - Pressāo arterial $80 \times 60$; temperatura 36,8 ; pulso $82 / \mathrm{min}$. Paciente em ótimas condições gerais com desenvolvimento somático e psíquico normais. Não havia gânglios palpáveis e o exame especial dos diferentes aparelhos nada revelou de anormal, inclusive do ponto de vista neurológico. Exame do segmento cefálico - Grande massa tumoral na região frontoparietal esquerda, ultrapassando ligeiramente a linha média; apresentava consistência dura, sendo indolor e firmemente aderida aos

Departamento de Neurologia da Faculdade de Medicina da Universidade de São Paulo (Prof. Adherbal Tolosa): * Neurocirurgião; ** Estagiário; *** Professor de Disciplina de Neuropediatria; **** Professor de Disciplina de Neurocirurgia; ***** Patologista. 
planos profundos. A palpação notava-se a presença de nodulações de tamanho variável com consistência mais mole sôbre a massa principal do tumor e nas suas vizinhanças (fig. 1). Exames complementares - Craniogramas: tumoracão óssea de grandes dimensões na região frontoparietal esquerda, ultrapassando a linha média por alguns centímetros; imagens alvéolo-císticas radiotransparantes, contendo granulações amorfas de grande densidade radiológica, nitidamente circunscritas por halo esclerótico; as tábuas ósseas são respeitadas, embora estejam adelgaçadas, e a díploe se apresenta consideràvelmente espessada; lesões semelhantes são observadas nas vizinhanças da principal, localizando-se a maior delas na região parietal média esquerda (fig. 2). Estudo radiológico do restante do esqueleto normal. Eletrencefalograma normal. Exame do liquido cefalorraqueano normal. Hemograma normal. Cálcio sérico $11 \mathrm{mg} / 100 \mathrm{ml}$. Fósforo sêrico 4,9 de $\mathrm{P}$ inorgânico por $100 \mathrm{ml}$. Angiografia pela artéria carótida esquerda normal.
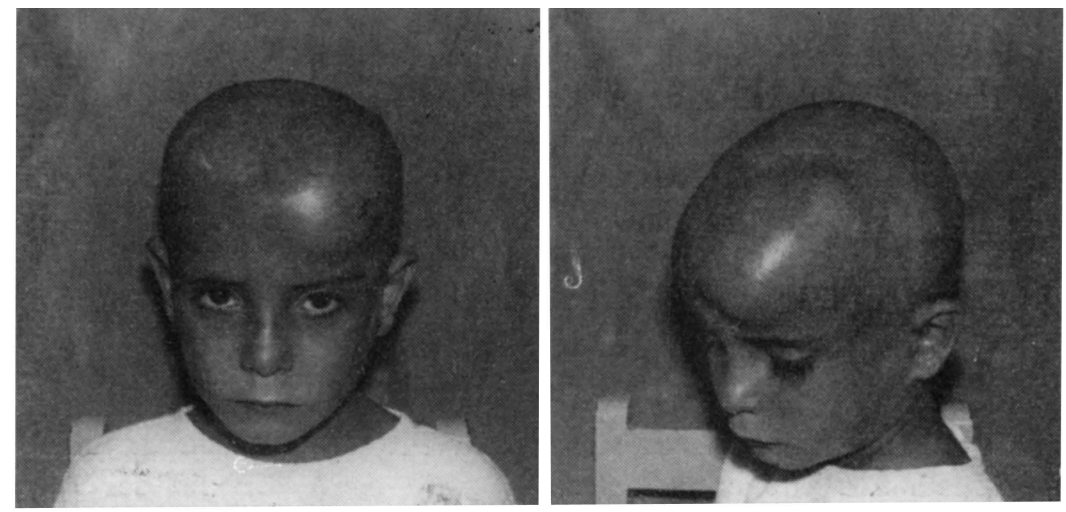

Fig. 1 - Fotografias do paciente D.P.A., observando-se volumosa tumoração na região frontotemporal esquerda $e$ um nódulo menor na região parietal do mesmo lado.
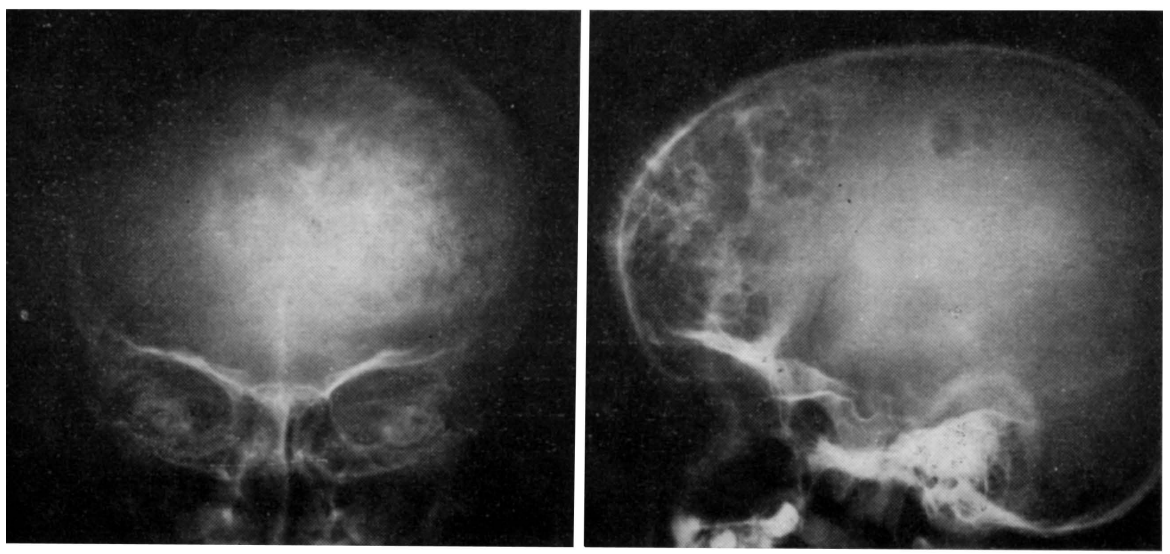

Fig. 2 - Caso D.P.A. Craniogramas mostrando tumor caracterizado por imagens alvéolo-cisticas radiotransparentes circunscritas por halo esclerótico. o quadro radiológico é típico de displasia fibrosa óssea do tipo pseudocístico. 
Do ponto de vista radiológico o quadro foi considerado como típico de displasia fibrosa de forma pseudocística. No entanto, a biopsia de um dos nódulos moles do tumor forneceu o diagnóstico de fibro-hemangioma. Sem diagnóstico preciso o paciente foi operado em 6-7-1967, sendo feita ampla incisão cutânea coronária. O descolamento da pele foi fácil, pois ela não estava firmemente aderida ao tumor. Este apresentava côr vinhosa e era muito vascularizado; sua superfície tinha numerosos nódulos que eram muito friáveis, enquanto que a massa principal da neoplasia tinha consistência óssea. Além das bordas do tumor o osso exibia coloração semelhante à da neoplasia, sendo mais mole que o normal. Outra tumoração de dimensões menores foi encontrada na região parietal média esquerda. Foram feitas diversas trepanaçōes ao redor das tumorações em regióes ósseas aparentemente normais. A seguir, mediante serra de aço flexível, foi completada a craniectomia, que incluiu tôda a região macroscòpicamente comprometida. A dura-mater tinha aspecto normal, não apresentando aderências com o tumor. Este, por sua vez, não chegava a destruir a tábua interna (fig. 3). O exame histopatológico revelou tratar-se de hemangioendotelioma maligno invadindo o tecido ósseo (fig. 4).

Após o ato cirúrgico surgiu adenopatia pré-auricular e cervical à esquerda. Suspeitando-se de metástases ganglionares foi feita biopsia de um dos gânglios cervicais que, no entanto, revelou linfadenite crônica não específica. O paciente foi então irradiado com cobaltoterapia, chegando a receber $3000 \mathrm{rds}$ em um mês de tratamento. Apesar disso começaram a se tornar evidentes nódulos na periferia da região óssea removida e novo craniograma revelou a presença de vários focos de osteólise indicativos de progressão do processo neoplásico. Tendo em vista o malôgro da telecobaltoterapia foi indicado tratamento quimioterápico, empregandose o Enduxan na dose de $50 \mathrm{mg}$ diários por via intravenosa. O paciente tolerou
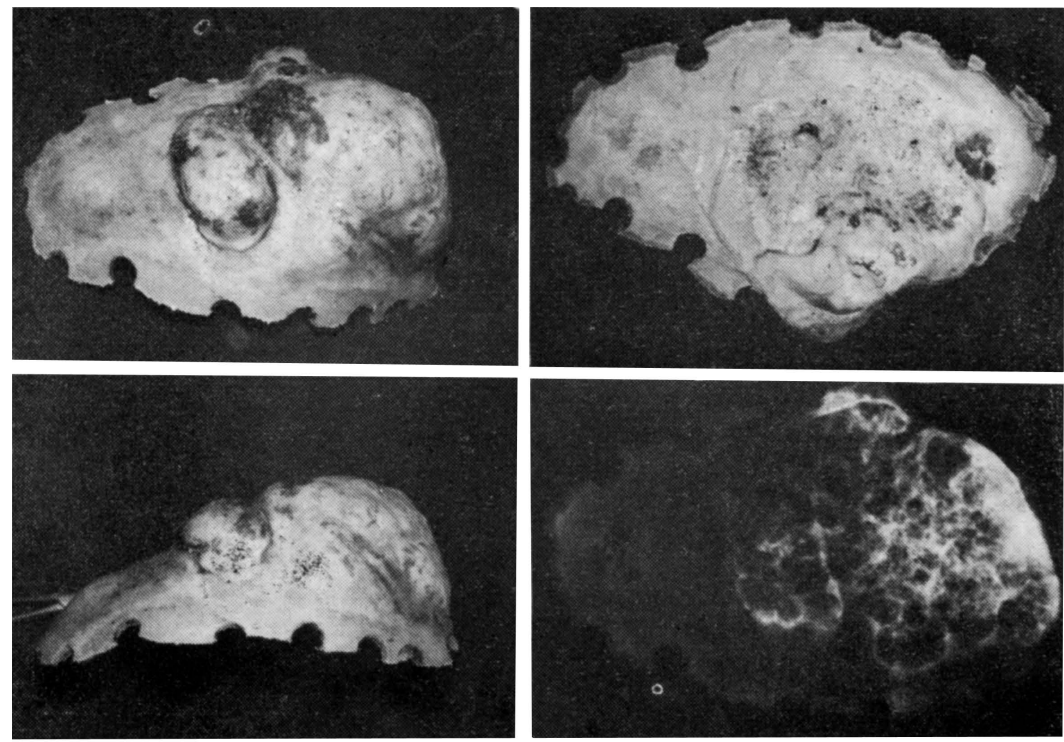

Fig. 3 - Caso D.P.A. Fotografias da peca cirúrgica, mostrando que o tumor não destruia as tábuas externa e interna, mas apenas espessava acentuadamente a díploe. Em baixo (à direita) vî-se uma radiografia da peça cimúrgica: imagens alvéolo-cisticas, contendo grânulos amorfos de grande densidade radiológica, circunscritos por halos escleróticos; o aspecto lembra o favo de mel. 
perfeitamente a droga e as massas tumorais desapareceram completamente depois de 35 dias consecutivos de tratamento. Vários craniogramas de contrôle, feitos após o término da terapêutica, mostraram o desaparecimento das lesões ósseas. O último exame radiológico do crânio, feito em 29-4-1968, mostrava sinais de osteogenese na região da craniectomia, não revelando mais lesão alguma em atividade.
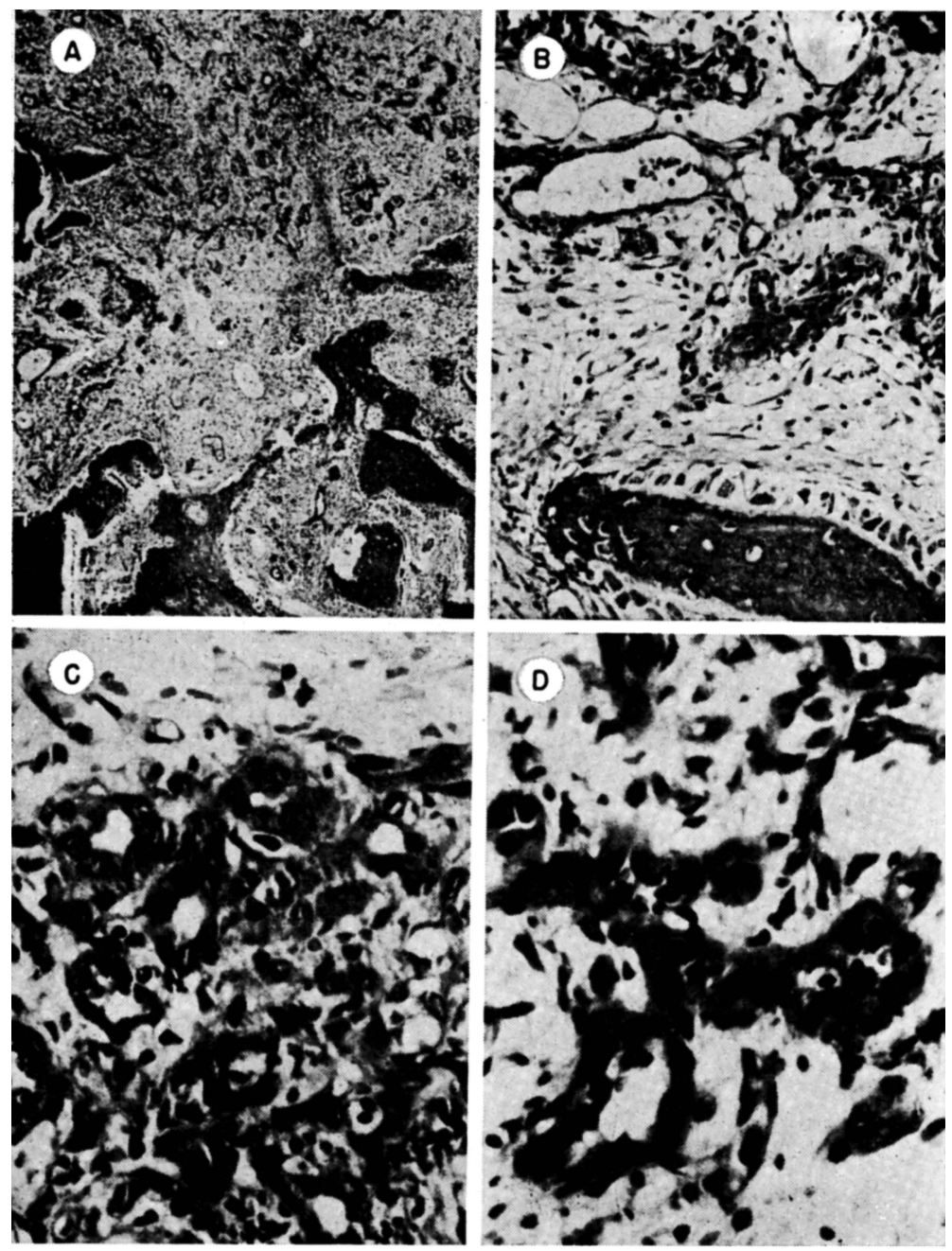

Fig. 4 - Caso D.P.A. Microfotografias da peça cirúrgica (coloração H.E.): em A, proliferação capilar intensa nos espaços medulares (pequeno aumento); em $B$, com maior aumento, vê-se vasos capilares proliferados nos espaços medulares do tecido ósseo, notando-se estratificação de células endoteliais; em $C$ e D, com grande aumento, observam-se capilares atipicos com endotélio tumefeito e células endoteliais com pleomorfismo nuclear. 


\section{COMENTÃ R I S}

No caso que estudamos embora não tenhamos prova decisiva de que a lesão tenha sido primitivamente óssea, pois no início do quadro houve aparentemente envolvimento das partes moles, o acometimento sempre predominou nitidamente no crânio. Durante o ato cirúrgico não foi notada invasão das partes moles, tanto superficiais como profundas, pela neoplasia, que se limitava pràticamente à diploe.

Os tumores vasculares, em virtude da grande dificuldade em se determinar sua histogênese, têm sido denominados da maneira mais diversa, o que dificulta sua classificação ${ }^{15}, 17,20$. Lichtenstein ${ }^{13}$ enquadra sob o nome de hemangioendotelioma maligno todos os tumores malignos genuìnamente vasculares, exceto os infiltrativos e metastatizantes (hemangiopericitomas) os quais são, de regra, extremamente malignos, já tendo dado metástases sangüíneas antes de serem localizados. Usamos neste trabalho o conceito de Lichtenstein, embora não se trate de assunto encerrado, pois Freilich e Coe ${ }^{6}$, ao registrarem um caso de lesão óssea primária maligna da escápula com metástases para os pulmões, fígado e baço, empregam o têrmo angiossarcoma para designar angiomas celulares nos quais a unidade é o vaso e não a célula endotelial, e o tecido neoplásico revela evidente tendência vasoformativa. Thomas ${ }^{22}$ divide os tumores vasculares malignos em angioendoteliomas e angiossarcomas, ambos celulares e compactos com proliferação endotelial ativa e capacidade de infiltração; o primeiro mostra tendência a reverter às estruturas mesenquimais primitivas e à neoformação vascular, enquanto que o angiossarcoma caracteriza-se pela proliferação do endotélio vascular, sendo predominantemente vasoformativo. Outros autores 10, 11, 12, 19 admitem três graus de maturação para os tumores vasculares sangüíneos malignos, sendo o hemangioendotelioma de malignidade intermediária: hemangiomas, hemangioendoteliomas e hemangioendoteliossarcomas. Turner e Kernohan ${ }^{23}$ também reconhecem três graus de malignidade progressiva entre os tumores vasculares: hemangioendotelioma, hemangioblastoma e hemangiossarcoma. A estrutura básica dêstes três grupos foi descrita como sendo essencialmente a mesma, exceto pela ascendente celularidade e maior número de mitoses. O tumor da célula endotelial é o melhor descrito e denominado hemangioendotelioma e duas são suas características principais: formação de células endoteliais atípicas e de tubos vasculares, apresentando estrutura de fibras reticulínicas com tendência a anastomoses livres ${ }^{13}$. A distinção entre o tipo celular endotelial e o pericitoma se faz pela coloração pela prata ${ }^{21}$ e pela microscopia electrônica ${ }^{18}$. Um fato bem salientado por Cabanne e col. ${ }^{3}$ e por Glasser ${ }^{7}$ é que o estudo histológico de vários cortes destas neoplasias, tanto primitivas como metastáticas, pode apresentar grande polimorfismo estrutural, havendo zonas com sinais tìpicamente malignos e outros com caracteristicas de benignidade. No caso que estudamos ocorreu provàvelmente êsse fato, pois a biopsia pré-operatória mostrou aspecto benigno, diagnosticado como fibro-hemangioma, ao passo que o estudo mais completo da peça operatória permitiu o reconhecimento de um hemangioen- 
dotelioma maligno. Lichtenstein ${ }^{13}$ não admite a transformação de um hemangioma benigno em hemangioendotelioma maligno, afirmando que êstes últimos apresentam desde o início características de malignidade.

Do ponto de vista clínico o nosso paciente não apresentou sintomatologia alguma durante tôda a evolução da doença. Usualmente êstes tumores provocam dor e edema, às vêzes de grande intensidade. Caquexia e outros sintomas de malignidade das neoplasias também costumam ocorrer quando o processo se encontra em fase avançada. Entre os exames complementares que fornecem subsídio importante para o diagnóstico, Carter e col. ${ }^{4}$ realçam o valor da angiografia que geralmente permite demonstrar de maneira clara a natureza vascular da neoplasia. No entanto, a carótido-angiografia foi normal em nosso doente.

Embora possam incidir em qualquer idade, os hemangioendoteliomas malignos são excepcionais durante a infância, ocorrendo, na maioria das vêzes, após os quarenta anos. Thomas ${ }^{22}$, entre 27 casos de sarcomas ósseos, descreve um angiossarcoma (hemangioendotelioma) em criança com 3 anos de idade. Há também um caso publicado de uma criança com 3 meses de vida, que apresentava neoplasia da mesma natureza na região maxilar ${ }^{9}$.

Entre as entidades que podem ser confundidas com neoplasias ósseas figura em lugar de destaque a displasia fibrosa óssea. No caso que ora relatamos o exame radiológico do crânio levou ao diagnóstico desta afecção, por serem as alterações estruturais encontradas típicas da displasia fibrosa pseudocística. Trata-se de doença benigna, de etiologia desconhecida, admitindo-se que represente combinação de defeitos embrionários de caráter geral e disfunção hipotalâmica 1, 5, 11, 12,13,14. Há discordância quanto à natureza genética desta moléstia; no entanto ela ocorre duas vêzes mais freqüentemente no sexo feminino. Cêrca de $80 \%$ dos casos incidem na primeira década da vida, tendo sido descrita inclusive em recém-nascidos.

As lesões esqueléticas da displasia fibrosa óssea resultam aparentemente de atividade pervertida do mesenquima osteogênico, que provoca a formação de cavidades preenchidas por tecido fibroso esbranquiçado, às vêzes granuloso, contendo ilhotas de cartilagem hialina, que conferem ao processo aspecto característico. O crânio figura entre as regiões mais atingidas pela doença. Radiològicamente, se observam áreas radiotransparentes de forma irregular, mais ou menos delimitadas por halos escleróticos, que dão ao conjunto o aspecto de um favo de mel. Clìnicamente, a maioria dos doentes não apresenta sintomatologia alguma, podendo, no entanto, ocorrer dores ósseas, fraturas patológicas e deformidades. A fosfatase alcalina está geralmente aumentada e o cálcio e fósforo são normais no sôro sangüíneo. Nas crianças pequenas esta moléstia comumente compromete vários ossos (forma polióstica); nestes casos são também freqüentes as alterações extra-esqueléticas, tais como manchas hiperpigmentadas na pele e distúrbios de esfera endócrina, especialmente a puberdade precoce em pacientes do sexo feminino. A associação de lesões ósseas, manchas cutâneas de côr "café-com-leite" e puberdade precoce constitui a sindrome de Mc Cune-Albright. Além 
disso, podem ocorrer crescimento e maturação precoces do esqueleto, hipertireoidismo, diabetes melitus e outros defeitos de desenvolvimento em numerosos órgãos.

Além da displasia fibrosa óssea, outras condições patológicas devem ser lembradas no diagnóstico diferencial do hemangioendotelioma maligno primitivamente ósseo. De maneira geral tôdas as causas de lesões osteolíticas e tumores com componente vascular importante são passiveis de confusão com esta afecção. Entre as mais importantes citaremos metástases ósseas de neoplasias situadas em outros órgãos, mieloma múltiplo, cistos ósseos solitários ou múltiplos, osteossarcoma, tumor de células gigantes, osteite fibrosa localizada, histiocitose (especialmente o granuloma eosinófilo), osteíte múltipla cística, neurofibromatose, fibroma osseificante, osteoma osteóide, sarcoma de Ewing e condroblastoma benigno.

Quanto ao tratamento, os hemangioendoteliomas malignos são pouco sensíveis à radioterapia que, quando muito, apenas retarda seu crescimento ${ }^{4}$. A conduta geralmente aceita é a que preconiza a excisão cirúrgica como medida exclusiva, ou seguida de radioterapia. No entanto, a avaliação dos resultados é muito difícil pela limitada experiência que todos os cirurgiões têm com êste tipo de neoplasia. Pinheiro ${ }^{16}$ refere resultado favorável em um caso de hemangioendotelioma da coxa com quimioterapia antineoplásica em circuito isolado (circulação seletiva); o tumor de grandes proporções desapareceu totalmente em 22 dias; no entanto, o paciente faleceu dois anos depois com recidiva do processo. Em nosso doente a excisão cirúrgica e cobaltoterapia em doses elevadas, não foram suficientes para impedir a progressão do tumor para as regiões ósseas vizinhas. O tratamento quimioterápico, com Enduxan intravenoso, provocou a cura clínica e radiológica da neoplasia, que persistia 6 meses após o término da terapêutica, havendo, inclusive, sinais de regeneração óssea normal.

A maioria dos casos de hemangioendotelioma maligno apresentam curto período de sobrevida, principalmente quando são acometidos órgãos de importância vital 2, 24. No entanto, Hauser e Constant 8 relatam o caso de um paciente com comprometimento de ambos os fêmores e óssos ilíacos, que sobreviveu 9 anos sem apresentar metástases clìnicamente evidentes. Jaffe 11,12 também cita casos que sobreviveram vários anos. Geralmente o prognóstico é mais favorável quando o hemangioendotelioma se situa na extremidade dos membros, pois as amputações podem ser amplas e radicais.

\section{RES U M O}

Os hemangioendoteliomas primitivamente ósseos são neoplasias muito raras e de diagnósticos clínico e radiológico difíceis. Em virtude de seu crescimento rápido, grande capacidade infiltrativa e metastatização precoce, o prognóstico é geralmente sombrio, mesmo com cirurgia radical seguida de radioterapia. 
Relatamos um caso de hemangioendotelioma maligno, localizado no crânio, em criança de 6 anos de idade, cujo diagnóstico radiológico foi de displasia fibrosa óssea. O doente foi operado, sendo feita exérese aparentemente total da neoplasia e, a seguir, irradiado com cobaltoterapia em doses elevadas; tais medidas, contudo, não impediram a progressão do processo neoplásico. A quimioterapia, com Enduxan intravenoso, determinou a cura clínica e radiológica do paciente. São discutidos vários aspectos referentes ao diagnóstico do hemangioendotelioma maligno, tendo em vista a grande confusão existente na literatura em relação à nomenclatura e classificação dêsses tumores.

S U M M A R Y

Malignant hemangioendothelioma of the skull in a chi?d.

The primary localization of hemangioendothelioma in the bone is very rare and the clinical and radiological diagnosis is often difficult. Due to the rapid growth, invasive properties and early metastatization, the evolution of these neoplasms is often progressive, despite the radical removal followed by radiotherapy.

A case of a malignant hemangioendothelioma of the skull in a 6-year-old male patient is reported. The radiological aspects supported the diagnosis of fibrous dysplasia of bone. The patient was operated on, and an apparently total removal of the tumor was performed, followed by cobaltotherapy; however, the growth of the neoplasm was not arrested. Thus, chemotherapy with intravenous Enduxan (50 mg per day) was employed during a month, with clinical recovery and radiological cure of the process. Some clinical features on the differential diagnosis of hemangioendothelioma are discussed due to the confusion on the terminology and classification of these tumors.

REFERẼ CIAS

1. BOENHEIM, F. \& Mc GAVACH, T. H. - Polyostotische fibrose dysplasie. Ergebn. inn. Med. Kinderheilk. 3:157, 1952.

2. BOTSFORD, T. W. - Tumors of the small intestine: a review of experience with 115 cases including a report of a rare case of malignant hemangioendothelioma. Amer. J. Surg. 103:358, 1962 .

3. CABANNE, F.; MiChIEls, R.; DUSSERRE, P. \& TUAILlon, P. - Hémangioendothéliomes du sein: étude anatomo-clinique de deux cas. Laval Med. $37: 579,1966$.

4. CARTER, J. H.; DICKERSON, R. \& NEEDY, C. - Angiosarcoma of bone: a review of the literature and presentation of a case. Ann. Surg. 144:107, 1956 .

5. CATEL, W. - Diagnostico en Pediatria. Salvat, Barcelona, 2.a ed., 1966.

6. FREILICH, L. B. \& COE, G. C. - Angiosarcoma: case reporte and review of the literature. Amer. J. Cancer. 26:269, 1936. 
7. GLASSER, A. \& REICHMANN, J. - Multizentrisches unilaterales hämangioendothelioma des hand-arm-skeletts. Brun's Beitr. klin Chir. 210:422, 1965.

8. HAUSER, E. D. W. \& CONSTANT, G. A. - Skeletal hemangioendothelioma: a case report. J. Bone Jt Surg. 30A:517, 1948.

9. HENRY, F. A. - Angiosarcoma of maxila in three month old infant. J. Oral Surg. 7:250, 1949.

10. HUECK, W. - Morphologische Pathologie. Georg Thieme Verlag, Leipzig, 1937.

11. JAFFE, H. L. - Fibrous dysplasia of bone. Bull. N. Y. Acad. Med. 22:588, 1946 .

12. JAFFE, H. L. - Tumors and Tumorous Conditions of the Bones and Joints. Lea \& Febiger, Philadelphia, ed. 2, 1961.

13. LiChtenstein, L. - Bone Tumors. Mosby, St. Louis, ed. 2, 1959.

14. LiCHTENSTEIN, L. \& JAFFE, H. L. - Fibrous dysplasia of bone: a condition affecting one, several or many bones, the graver cases of which may present abnormal pigmentation of skin, premature sexual development, hyperthyroidism or still other extra-skeletal abnormalities. Arch. Path. 33:777, 1942.

15. Mc CARThY, W. D. \& PACK, G. T. - Malignant blood vessel tumors: 56 cases of angiosarcoma and Kaposi's sarcoma. Surg. Gynec. Obstet. 91:456, 1950.

16. PINHEIRO, L. C. - Da quimioterapia antineoplásica em circuito isolado. Rev. brasil. Cirurg. 45:252, 1963.

17. POLLAK, A. - Angiosarcoma of the sternun. Amer. J. Surg. 77:522, 1949.

18. RAMSEY, H. J. - Fine structure of the hemangiopericytoma and hemangioendothelioma. Cancer 19:2005, 1966.

19. RoBBINS, S. L. - Textbook of Pathology, W. B. Saunders, Philadelphia, ed. 2, 1962 .

20. STOUT, A. P. - Hemangioendothelioma: a tumor of blood vessels featuring endothelial cells. Ann. Surg. 118:445, 1943.

21. STOUT, A. P. - Tumors of the soft tissue. Armed Forces Institute of Pathology, Washington, 1953.

22. THOMAS, A. - Vascular tumors of bone: a pathological and clinical study of 27 cases. Surg. Gynec. Obstet. 75:777, 1942.

23. TURNER, O. A. \& KERNOHAN, J. W. - Vascular malformations and vascular tumors involving the spinal cord: a pathological study of 46 cases. Arch. Neurol. Psychiat. 46:444, 1941.

24. VIGO, N. J.; SCHAPOSNIK, F. \& LAGUENS, R. - Renal hemangioendothelioma. Rev. argent. Urol. 33:107, 1964. 